EPJ Web of Conferences 87,04001 (2015)

DOI: $10.1051 /$ epjconf/ 20158704001

(C) Owned by the authors, published by EDP Sciences, 2015

\title{
Summary of Technology sessions at EC18
}

\author{
Gregory G. Denisov ${ }^{1, a}$ \\ ${ }^{1}$ Institute of Applied Physics Russian Academy of Sciences, Nizhny Novgorod, Russia
}

\begin{abstract}
A summary of Technology session in EC18 is made. 18 presentations were presented during the workshop. These presentations can be categorized into two main subjects those are gyrotrons and transmission lines.
\end{abstract}

Among 18 presentations in the technology sessions, 7 presentations were done by authors from Japanese institutions, 8 from EU ( 5 Germany), 2 by Russians and 1 by US. 10 papers describe achievement in gyrotron development, other show progress in transmission line components and microwave pattern measurement technique. Besides gyrotrons papers were devoted new results in FADIS, Remote Steering System for W\&-X, several presentation were done on alignment and monitoring of transmission lines. The presentation of F4E overviewed "Status of Europe's contribution to the ITER EC system".

\section{Gyrotrons}

1.1. Great progress was demonstrated in gyrotron development. The most developed gyrotrons are the tubes for ITER. The gyrotron prototypes for ITER showed parameters corresponding to ITER requirements (see Table 1). Now the main part of activity is spent to ITER gyrotron reliability.

Table 1. Gyrotrons for ITER, $170 \mathrm{GHz}$

\begin{tabular}{|l|l|}
\hline Main results & Institution/Company \\
\hline $1 \mathrm{MW} / 55 \% / 800 \mathrm{~s}$ and & JAEA/Toshiba, Japan \\
$0.8 \mathrm{MW} / 57 \% / 3600 \mathrm{~s}$ & \\
\hline $1 \mathrm{MW} / 53 \% / 1000 \mathrm{~s}$ and & IAP/GYCOM, Russia \\
$1.2 \mathrm{MW} / 53 \% / 100 \mathrm{~s}$ & \\
\hline
\end{tabular}

1.2. High-level parameters were also achieved with long-pulse 140 GHz gyrotrons (see Table2). The development continues.

Table 2.

\begin{tabular}{|l|l|l|}
\hline & Main results & Company \\
\hline W7-X, IPP & $0.9 \mathrm{MW} / 45 \% /$ & Thales, EU \\
& $1800 \mathrm{~s}$ & \\
\hline EAST, ASIPP & $0.7 \mathrm{MW} / 49 \% /$ & GYCOM, Russia \\
& 1000 & \\
\hline
\end{tabular}

\footnotetext{
${ }^{\mathrm{a}}$ Corresponding author: den@appl.sci-nnov.ru
}

1.3. There are numerous development of gyrotrons at different frequencies for different plasma installations: $105 \mathrm{GHz}, 110 \mathrm{GHz}, 117 \mathrm{GHz}, 82$ $\mathrm{GHz}, 77 \mathrm{GHz}, 154 \mathrm{GHz}, \ldots$ So far the results are not so impressive as for $140 \mathrm{GHz}, 170 \mathrm{GHz}$ gyrotrons. The gyrotrons tested with relatively short pulses $(<10 \mathrm{sec})$, lower power $(<0.8 \mathrm{MW})$ or lower efficiency $(<40 \%)$.

1.4. 2- and multi-f MW gyrotrons are under rather intensive development. In particular, 2- and 4frequency gyrotrons for ASDEX-Upgrade: $105 \mathrm{GHz} / 140 \quad \mathrm{GHz}(0.7 / 0.9 / 10 \quad \mathrm{sec}) \quad$ and $105 / 117 / 127 / 140 \mathrm{GHz}$ by IAP, IPP and KIT. Also very good results have been already shown by cooperation of JAEA/Toshiba: 170/137/104 GHz and $110 \mathrm{GHz} / 138 \mathrm{GHz}(1 \mathrm{MW} / 1 \mathrm{MW} / 10 \mathrm{sec})$. For Japanese gyrotrons the application of a triode gun resulted in possibility to operate at modes with the same caustics and similar output wave beams at different frequencies. First successful attempt to braze elliptical Brewster window was done by KIT. The window was installed for short pulse $(\sim 1 \mathrm{~ms})$ multi-frequency gyrotron.

1.5. There are several projects aiming elaboration of higher power (1.5-2MW) gyrotrons. The current results are shown in Table 3. Long pulse operation $(\sim 100 \mathrm{sec})$ has not been shown yet.

Table 3.

\begin{tabular}{|c|c|}
\hline Result & Country \\
\hline $170 \mathrm{GHz} / 1.5 \mathrm{MW} / 48 \% / 2.5 \mathrm{sec}$ & Russia \\
\hline $170 \mathrm{GHz} / 1.94 \mathrm{MW} / 43 \% / 0.003 \mathrm{sec}$ & EU \\
\hline $117 \mathrm{GHz} / 1.8 \mathrm{MW} / 41 \% / 0.005 \mathrm{sec}$ & US \\
\hline $77 \mathrm{GHz} / 1.7-1.8 \mathrm{MW} / 1-2 \mathrm{sec}$ & Japan \\
\hline
\end{tabular}

1.6. Estimates of higher frequency gyrotrons for future plasma installations $(230-300 \mathrm{GHz})$ were done. They show that $0.2-0.3 \mathrm{MW}$ gyrotrons can be made on the base of easily commercially available magnets with $100 \mathrm{~mm}$ bore diameter. $1 \mathrm{MW}$ tubes 
require at least $180 \mathrm{~mm}$ diameter magnets. $0.2 \mathrm{MW} /$ $260 \mathrm{GHz} / \mathrm{CW}$ is now in fabrication by GYCOM.

1.7. New ideas. Two novel ideas were proposed (IAP) to improve gyrotron operation:

- Wavebeam switching inside a gyrotron. Short pulse experiment with $170 \mathrm{GHz}$, TE28.12 mode was successful;

- Frequency/Phase Locking of MW gyrotrons in order to provide the same frequency/phase of many gyrotrons, enhance gyrotron efficiency and radiation spectrum. Experiments are going on. Success may change EC systems essentially.

\section{Transmission line components and microwave pattern measurement}

To illustrate the new developments just a few short abstracts were placed in the summary:

A study of mode purity improvement in the ITER relevant transmission line. Y. Oda et al (JAEA)

In JAEA, ITER relevant transmission line (TL) was examined using a $170 \mathrm{GHz}$ high power gyrotron. In this paper, the activity to improve of mode purity in TL is reported. The TL test stand in JAEA is composed of 63.5 $\mathrm{mm}$ diameter corrugated waveguide (WG) system. The TL test stand delivers $170 \mathrm{GHz}$ high power RF from the gyrotron to dummy loads or the ITER equatorial port launcher (EL) mockup. The length of long distance TL which includes 4 miter bends, a couple of polarizer, and two WG switch was $40 \mathrm{~m}$. The RF power from gyrotron was coupled into TL inlet at a matching optical unit (MOU) with $95 \%$ of LP01 mode purity. Finally $91 \%$ of LP01 mode purity was achieved at the end of $40 \mathrm{~m}$ length TL.

Development of power/polarization monitor in the ECRH transmission line. R. Makino, et al. Department of Energy Engineering and Science, Nagoya Univ., Nagoya 4048603

For optimization of electron cyclotron resonance heating (ECRH), it is important to measure power and polarization states of injected millimeter-waves. The development of real-time monitor that enables simultaneous detection of the injected power and polarization state is required.

The power/polarization is measured by the monitor composed of bi-linear polarization directional coupler and heterodyne interferometer that enables to detect the power and the phase difference of two orthogonal polarizations. IF signals are measured by fast ADC which has sampling rate of $800 \mathrm{MHz}$ with FPGA (Field Programmable Gate Array).

Multifrequency Notch Filter for Millimeter Wave Plasma Diagnostics Based on Photonic Bandgaps in Corrugated Circular Waveguides. D.Wagner et al. Max-PlanckInstitut für Plasmaphysik, EURATOM-IPP, Boltzmansstr.2, D-85748 Garching
A filter based on an oversized circular corrugated waveguide with a corrugation period satisfying the Bragg condition can provide several defined stop bands. The filter will protect a new inline ECE diagnostic at ASDEX Upgrade where a multi-frequency ECRH system with several two-frequency gyrotrons $(105$ and $140 \mathrm{GHz})$ is in operation. The filter consists of an oversized circular waveguide section with radial corrugations and smoothwall nonlinear tapers to connect the oversized waveguide section to standard circular D-Band waveguides.

Development of a Millimeter-Wave Beam Position and Profile Monitor for Transmission Efficiency Improvement in an ECRH System. T. Shimozuma, et al. National Institute for Fusion Science, Toki-city, 509-5292, Japan In a high power ECRH system with long-distance transmission lines a real-time beam-position and -profile monitor (BPM) is required to evaluate the position and profile of a high power. Two-dimensional array of Peltier devices is installed and aligned on the atmospheric side of a thin miter-bend reflector. A mmw-beam is reflected on the mirror surface of the miter-bend and partly absorbed in the reflector plate. The generated heat by Ohmic loss diffuses to the outside of the reflector and removed by the Peltier devices. The two-dimensional temperature profile of the miter-bend reflector can give the real-time information of the position and profile of the mmw beam

Research and Development of 2-frequency (110/138 GHz) FADIS for JT-60SA ECH/ECCD Experiments. $H$. Idei, et al. Research Institute for Applied Mechanics, Kyushu Univ., Kasuga, 816-8580, Japan

The local current driven by ECCD has been in operation to suppress NTM mode activities in the tokamak. Synchronous switching for the mode rotation using the FADIS was proposed for more effective suppression. The 2-frequency $(110 / 138 \mathrm{GHz})$ gyrotron has been developed for a JT-60SA ECH/ECCD system. The FADIS for the 2frequency gyrotron system is developing under a JAEA collaboration with Kyushu University. A square corrugated waveguide diplexer system with 2 resonant rings was considered as one of attractive FADIS systems.

\section{Diamond Window Diagnostics for Nuclear Fusion Applications - Early Concepts \\ F. Mazzocchi, G. Aiello, P. Spaeh and T. Scherer. Karlsruhe Institute of Technology, Association KIT- EURATOM, P.O. Box 3640, D-76021 Karlsruhe, Germany}

The required diagnostics include arc detection, tritium detection, microwave reflected/transmitted power and disk temperature. The diagnostics devices to be implemented must have a compact, simple and flexible layout, with a rugged design, in order to maximize serviceability and durability in the harsh environment they will face.

Development of Resonant Diplexers for high-power ECRH - Status, Applications, Plans 
W. Kasparek, et al. Institut f. Grenzflächenverfahrenstechnik und Plasmatechnologie, D-70569

Stuttgart.

The development of diplexers for ECRH has been pursued at a number of institutes because of their attractive variety of applications: Power combination, non-mechanical, electrically controlled switching (of combined beams) between launchers with tens of $\mathrm{kHz}$, and discrimination of low-power ECE signals from highpower ECRH is feasible. The resonant diplexer, which employs a resonator for Gaussian beams and mode converting horns to match the connecting HE11 waveguides, was tested extensively at the $140 \mathrm{GHz}$, W7$\mathrm{X}$ ECRH system . Present diplexer versions feature direct corrugated waveguide inputs, owing to the use of ring resonators with phase-reversing mirrors matched to HE11 fields. Low-power measurements of such a diplexer show high performance, close to theory.

Remote-Steering Launchers for the ECRH system on the Stellarator W7-X. W. Kasparek et al. Institut für

Grenzflächenverfahrenstechnik und Plasmatechnologie, Univ. Stuttgart.

At the stellarator Wendelstein7-X (W7-X), ECRH system consists of 10 gyrotrons operating at $140 \mathrm{GHz}$, with power up to $1 \mathrm{MW} \mathrm{cw}$ each. The transmission from the tubes to the plasma is performed optically via two multibeam waveguides. The power will thus be fed via Remote-steering launchers (RSLs). The remote-steering properties are based on multi- mode interference in a corrugated square waveguide (length $\mathrm{L}=4.6 \mathrm{~m}$, width $\mathrm{a}=$ $50.2 \mathrm{~mm}$ ). The movement of the steering mirror is optimized such that the effective waveguide length is matched to the angle $\phi$ of the input and output beams; thus, an extension of the steering range of $-15^{\circ}<\phi<15^{\circ}$.

\section{Conclusion}

Great progress in last two years was shown in EC technology including development of gyrotrons, TL, components, calculation and measurement methods. 